\title{
A Conceptual Framework for Archaeological Data Encoding
}

\author{
Sveta Matskevich and Ilan Sharon*
}

\section{Introduction}

The work presented here evolved within the framework of the Tel Dor project. Dor is a major port town on the Mediterranean, between present-day Tel Aviv and Haifa in Israel. ${ }^{1}$ It was active from the Middle Bronze Age to the Roman era. The present Dor expedition is the custodian of a long history of excavations and archaeological research that started in the early twentieth century and still continues. ${ }^{2}$ Such a "long durée" excavation poses particular challenges for data curation. The following remarks describe the different excavation projects conducted at Dor and the datasets they produced.

In 1922-1923, John Garstang, then director of the British School of Archaeology in Jerusalem, conducted two excavation seasons on the tell, ${ }^{3}$ digging the temple compounds in the western part of the mound and placing a probe trench through the southern slope, down to bedrock at the shore of the Southern Bay. Our search for Garstang's original records at the Rockefeller Museum and the Palestine Exploration Fund uncovered some plans (essentially the same ones published in the preliminary reports), ${ }^{4}$ photographs, and partial lists of finds. Nothing remained of the site grid he established, but it can be approximated from the extant remains of the temples. We do not know what kind of registration system he used.

In the 1950s, the regional antiquities inspector, Joseph Leibowitz, conducted salvage excavations around the tell. He was the first to locate and excavate the

\footnotetext{
* The research was supported by a postdoctoral fellowship funded by the Zinman Institute of Archaeology at the University of Haifa, Israel and Tel Dor Archaeological Project.

1 geo:32.617428, 34.916364.

2 For an up-to-date bibliography on Tel Dor, see $<$ http://dor.huji.ac.il/bibliography.html $>$ (accessed February 22, 2018).

3 Tell: an artificial mound formed as a result of successive cycles of construction, occupation, and destruction, sometimes separated by periods of abandonment.

4 Garstang 1924a; 1924b.
}

(C) SVETA MATSKEVICH AND ILAN SHARON, 2018 | DOI 10.1163/9789004375086_003 
Roman theater to the north and the church to the southeast. Some years ago, Leibowitz's heirs gave us some of his notebooks containing field notes and the beginning of an unfinished site report. These constitute the only known records of his excavations, except for a brief published note. ${ }^{5}$

The church was excavated again by Claudine Dauphin in $1979-1983 .{ }^{6}$ Dauphin's expedition produced several articles but no final report. We do not possess any of the original field records. Shimon Gibson, who worked with Dauphin, also conducted some surveys on and around the tell. ${ }^{7}$

Underwater exploration, as well as probes and surveys of maritime installations along the beach, began in the mid-1970s and continued in the 1980s, coinciding with the first years of large-scale excavation on the tell. These investigations were conducted by different people, including Avner Raban and Michal Artzi from the University of Haifa's Center for Maritime Civilizations, and Shelley Wachsman, Sean Kingsley, and Kurt Raveh, who were working for the Israel Department of Antiquities at the time. The expeditions were loosely collaborative, ${ }^{8}$ but the records of each were managed independently. Even within the maritime exploration, each subproject was conducted independently, often with a local grid and datum. The Haifa excavators used the classic "Israeli" recording system with the locus as a primary spatial unit, ${ }^{9}$ and they managed their records through a field diary, a daily top-plan, and a set of preprinted forms borrowed from the Tel Akko excavation. ${ }^{10}$ We do not have the records of the other teams, nor do we know what kind of registration systems they used. Since these various expeditions never shared their raw data (with each other or with the tell excavations), the compatibility of their field

5 Leibowitz 1950.

6 Dauphin 1984.

7 Dauphin and Gibson 1993.

8 Stern et al. 1995 .

$9 \quad$ About the recording system, see Aharoni et al. (1973). Locus (pl. loci): the basic spatial unit in most recording systems in Near Eastern Archaeology. The exact denotation of this term (i.e., the archaeological entity that is modeled by the abstract unit) can vary among different systems. Spatial unit: refers to a locational unit of excavation defined in absolute coordinates, relatively to the site grid, or to architectural features and other units in its vicinity.

10 Daily top-plan: a daily graphical record of an excavation area or part of it. The background plan shows all architectural features extant in the area on that particular day. The foreground information reflects how the excavation proceeded during the day. It comprises several types of data, such as outlines of excavation units, elevations, and the registration numbers and coordinates of finds. For the Tel Akko excavation, see Raban (1993). 
records was never questioned. However, the recently launched joint land-sea excavation (discussed below) necessitates the integration of these datasets.

The next extensive excavation of the tell was initiated in 1980 by Ephraim Stern of the Hebrew University of Jerusalem. The recording system employed by the team at the very beginning was a slightly different version of the "Israeli" system, borrowed from the Tel Batash excavation. ${ }^{11}$ It was altered considerably during the first ten campaigns ${ }^{12}$ and somewhat less during the next decade. ${ }^{13}$ Starting from the mid-1980s, recording procedures were written down for the purpose of instructing new staff members, and in 1991 the recording system was described in the first edition of the Dor Staff Manual. ${ }^{14}$

Even though one of the present authors was involved with this project since its initiation, from the point of view of recording technology, 1980 might as well be antediluvian. Naturally, no computers were available (the first Dor database, which was alphanumeric, was established in 1989). All record-keeping was of the pen-and-paper type. There were no photocopiers, either: all sketch plans (e.g., daily top-plans) and detail drawings were manually retraced (blueprints of the main phase plans were produced after the season). All records were one-off; if a record was lost or destroyed, it was gone. Digital photography was two decades into the future, and even fast developing and printing of film was not locally available. Photographs were taken once a week, and it was necessary to wait until the next week to see them developed. The contact prints were then pasted into albums. The first site grid (actually, not a full grid but a master $\mathrm{N}-\mathrm{S}$ line) was established with surveying rods aligned with a compass and distanced with a tape measure. It had to be redone as early as 1982 with a theodolite, but it was not until the mid-199os that an Electronic Distance Measurement(EDM)instrumentwas used on site (mounted on an optical theodolite). ${ }^{15}$ For reasons of backward compatibility, our current Dor expedition still uses the arbitrary site grid (and site datum) established in 1980.

\footnotetext{
$11 \quad$ Mazar 1997, 15-19.

12 Sharon 1995b.

13 Zorn, Sharon, and Gilboa, in press.

14 Zorn 1991.

15 Electronic Distance Measurement (EDM): an instrument that uses reflected light (infrared, laser, microwave) to calculate distances to remote objects; the models produced in the 1970 s through the 1990 s were mounted on top and externally connected to a theodolite. Newer models, in which a digital theodolite and an EDM are integrated within the same instrument, are known as "Total Stations." Theodolite: a surveying instrument with a rotating telescope for measuring horizontal and vertical angles.
} 
1980 was still the Age of Innocence in other respects, Although David Clarke had already proclaimed Archaeology's loss of innocence in 1973, ${ }^{16}$ Near Eastern Archaeology was still blissfully normative in 1980. The impact of the "New Archaeology" would only be fully felt later in the decade, followed closely by postprocessualism. ${ }^{17}$ These powerful swings of the theoretical pendulum should have had — but, we will argue below, did not have — an effect on the way data was observed and recorded in Levantine Archaeology. ${ }^{18}$

The present expedition was launched in 2003, at which time the recording system was again revamped (by one of the present authors) to accommodate all the above technologies. ${ }^{19}$ As part of our mission, we set out to locate all the available records of prior excavations. Fully digitizing them proved infeasible, however. Handwritten and hand-drawn records were scanned and attached as auxiliary documents to the appropriate database entities.

Nor are the problems of record consolidation limited to legacy data. In 2016, the land and maritime operations were reunited as Assaf Yasur-Landau joined our team to relaunch Avner Raban's operation. This not only necessitated the incorporation of Raban's data but also introduced problematics relating to (shallow) undersea excavation. For example, while working with loci is in principle possible underwater, keeping them bounded may prove difficult, as the sands shift in the bottom of the bay from day to day.

In 2017, working with the Israel Nature and Park Authority and the Israel Antiquities Authority (IAA) in anticipation of the opening of the Dor National Park to the public, we conducted a small test excavation north of the tell. For this excavation, we decided to use the IAA's DANA registration system. ${ }^{20}$ DANA is in many respects a more advanced database than ours, but a facile data import is not one of its merits. Therefore, it was decided it would be easier to export the data from DANA to the Dor system than vice versa. This introduced new

16 "The loss of disciplinary innocence is the price of expanding consciousness; certainly the price is high but the loss is irreversible and the prize substantial" (Clarke 1973, 6).

17 New Archaeology: an approach, first advocated in the 196os, that argued for an explicitly scientific framework of archaeological method and theory, in which hypotheses are rigorously tested rather than simply described (Renfrew and Bahn 2008, 582). Post-processualism: a number of developments in archaeological theory of the late 1980s and the 1990s; they are characterized by the denial of all or part of the positivistic movement of the 1960s-1970s and pursuing interpretational approaches (Renfrew and Bahn 2008, 491).

18 Levy and Holl 1995, 4-5, and references therein.

19 An up-to-date version of the Dor staff manual is available at $<$ http://dor.huji.ac.il/staff_ manual.html> (accessed June 12, 2017).

20 Digital Archaeology and National Archive (DANA): software for archaeological field recording developed by the Israel Antiquities Authority. 
compatibility issues that should be resolved systematically if similar enterprises are to continue in the future.

Currently, we are also initiating wider collaborations. Several projects working in the northern coastal region are forming the "Southern Phoenicia Initiative" to jointly pursue goals broader than those of the individual sites. Some of the Dor staff, including one of the present authors, are pursuing spinoff projects under this umbrella. These not only introduce further data-transfer and foreign-database-access issues, but they also require that typologies, chronological schemes, and other working protocols (e.g., sifting protocols) of the participating expeditions be at least commensurable. In the latter case, ontologies or thesauri enabling the translation of one project's terminology into another's need to be constructed.

Underlying the issues particular to the Dor project are challenges facing the digital-humanities community as a whole: How can digital data be curated for the long term? Can interoperability among different registration systems be achieved? Can meta-databases (for Archaeology as well as for other disciplines and interdisciplinary projects) be constructed on a national or transnational scale?

Because our work at Dor must tackle so many of the abovementioned issues, it is an appropriate starting point for thinking about the conceptual basis of archaeological data recording. What, if any, are the common denominators of all excavation-recording systems, or at least those of roughly compatible complexes, such as Near Eastern tell excavations? What should be the logical structure of a database that might accommodate all the permutations of such systems? Such an inquiry is quite technical, but it touches the very theoretical foundations of our discipline.

\section{Theoretical Background}

The notion of a hierarchy of theoretical concepts, with observations at its base and "grand" or "unified" theories at its apex, is part of the so-called "received view" of the logical-positivist school of philosophy of science of the early- to mid-twentieth century. ${ }^{21}$ Each level of this hierarchy forms an interpretation of the level[s] below and introduces increasingly abstract theoretical terms. Logical positivists used this notion in their (unsuccessful, many would say today) quest to rid science of metaphysics and to anchor "non-observables" such as "energy," "gene," or "society" solely in empirical facts in a rigorously logical

21 Losee 2001, 159-160, 171-172. 
manner. ${ }^{22}$ Low-level theory, in this layered model of the structure of science, involves the initial mapping of data onto primitive theoretical entities (e.g., "length is the property measured by a ruler") as well as protocols and procedures of data retrieval ("length should be measured from one end of an entity to the opposite end") and summaries of data (e.g., statistical analysis).

A parallel and probably dependent model, positing a hierarchy of theories, developed in the field of social theory, closely associated with the work of sociologist Robert K. Merton. Just like the positivist philosophers (who mainly used physics as the model of a "mature" science), Merton was bothered by the disjunction between "low" and "high" theory. ${ }^{23} \mathrm{He}$ argued that no amount of "low theory" - descriptive, empiricist, or statistical studies of individual societies or social attributes—can by itself produce "grand" theory—-the various "isms" of social thought. These are mostly a product of social philosophy rather than of empirical study and are often produced with very little (or even erroneous) factual support. To counter this deficiency, Merton advocated a program of "middle range" theories. These should be closely tied to empirical studies and produce testable propositions. They should not be total theoretical systems that attempt to cover all aspects of social life with a limited set of "universal laws." In time, though, they might develop into a unified theory by a process of inclusion, whereby a "higher" theory is proposed that subsumes several "lower" theories as special cases.

Just how much each of these conceptions of hierarchy within theoretical constructs affected Lewis Binford's concept of "middle-range theory" is not quite clear. ${ }^{24}$ In his initial article, he refers to neither. Nonetheless, in view of his disciplinary commitment to anthropology and his abiding loyalty to the tenets of logical positivism, ${ }^{25}$ there can be no doubt that he was well aware of both. Binford did give middle-range theory a uniquely archaeological twist: the particular challenge of archaeology is reconstructing the behavioral patterns of ancient societies from material remains (in Binford's language "inferring dynamics from statics"). Thus, for him, the ultimate aim - general, or "high," theory-is providing an explanation for cultural change (others would say this is simply anthropological theory). Systematics of the material record per se (e.g. stratigraphy, typology, etc.) is for him apparently the domain of "low" theory.

\footnotetext{
22 For an example of a logical positivist, see Hempel (1952).

23 Merton 1949.

24 Binford 1977.

25 "Archaeology is Anthropology or it is nothing" (Binford 1962, 217, quoting Willey and Phillips 1958, 2). "The accuracy of our knowledge about the past can be measured" (Binford $1968,17)$.
} 
We say "apparently" here, because Binford, significantly, never quite defines it. His proposed middle-range theory should be the linchpin connecting the two: a set of "laws" specifying how human dynamics can be "read" in the static archaeological record. ${ }^{26}$ For Binford, that meant primarily ethnoarchaeology. Only in the present, he argues, can one observe how dynamics are statically encoded. However, certain other types of research (such as site formation processes and experimental archaeology) are also within the scope of middlerange theory.

These connected, but not identical, definitions of "middle range" have been a source of some confusion. ${ }^{27}$ Raab and Goodyear assert founders' rights for the use of "middle range" in Archaeology, and hence that any definition different from theirs (i.e., Merton's) is mistaken. Because of this "confusion" (and due to the lack of any explicit definition of what constitutes "low-range") the scope of the latter is also vague. There is no doubt that the subject of our discussion here, registration systems - how practitioners view, denote, and record their data-should be considered "low" under almost any definition. Note, however, that even a simple label like "Wall X" (rather than "Unit X: consolidated stone depositional feature, the nature, function, and meaning of which is to be determined") assumes human builders and human intent. It thus cuts right through Binford's hierarchy without stopping at the middlerange level. Likewise, the definition of some category of artifacts as a "type" involves all kinds of assumptions of what types of attributes and variability people might find relevant. ${ }^{28}$ Another source of ambiguity is the overlap between "low level theory" and "methodology." A method is a way of doing. It requires some active, manipulative aspect, which not every theoretical construct needs to possess. Also, there are methodological issues with little or no theoretical baggage (e.g. the way in which the site grid is labeled, or how to balance a dumpy-level). Nevertheless, the two fields largely intersect and there can be no clear dividing line where method ends and theory begins. Yet, the fact that "method" and "theory" are put into different compartments in the archaeologist's toolbox often leads to dissonance between one's views of [high] theory and the field methodology one uses.

26 Static archaeological record: one of the keywords of the middle-range theory in Archaeology; it refers to all findings and the fact that, although uncovered almost simultaneously and in close physical proximity, they represent some diachronic reality.

$27 \quad$ Raab and Goodyear 1984.

28 Artifact: any portable object used, modified, or made by humans (Renfrew and Bahn 2008, 578). 
One of the present authors surveyed the historical development of registration systems in Levantine Archaeology. ${ }^{29}$ She noted that the development of the method and theory did not follow the same path. The "high" theory professed by practitioners tended to reflect—usually with some time lag - the changing fashions in general archaeological thought. These often vary between intellectual generations, with students taking stances that oppose those of their professors. With registration systems, on the other hand, practitioners tend to adopt whatever schemes they were first exposed to. Change, when it does occur, occurs by accretion. New technologies or techniques are absorbed into existing systems ad hoc, in whatever manner would least disrupt the extant framework.

The "New Archaeology" of the 196os to 1980s vauled scientific methods and exact measurements over impressionistic description and interpretation. A highly structured registration system, in which each observation is compartmentalized to a mandatory field and reduced to a measurement or a code, would fit such a positivistic vision much better than a rambling journal. However, by the time technologies of data collection and processing (such as digital measuring devices and relational databases) were readily available in the field, "high" theory was switching to post-processualism.

At the same time, the debates between processual and post-processual ideas were waged primarily over the high- and middle-range theory, ${ }^{30}$ and they rarely reached the basics of method..$^{31}$ This is odd, considering that one widely recognized flaw of the positivist program is in the realm of "low" theory. According to many, and not only rank postmodernists, the fact: theory dichotomy, upon which the "layered" model of scientific language is based, is a fallacy. Positivism failed in establishing formal criteria to distinguish between observation and interpretation (or "fact" and "theory"): "All our language is thoroughly theory-infected ... The way we talk, and scientists talk, is guided by the pictures provided by previously accepted theories ... Hygienic reconstructions of language such as the positivists envisaged are simply not on."32 Kaplan fa-

\footnotetext{
29 Matskevich 2015.

30 Processual (in Archaeology): during the 1960s and 1970s, an approach to interpreting the past via generalized cultural processes; it is based on a belief that the dynamics of the development of societies have regularities that can be applied to chronologically and geographically remote instances.

See Hodder $(1997,691-693)$ for an exception that proves the rule, with a few further references therein.

Van Fraassen 1980, 14. See also Kelley and Hanen (1988, 8-16) and Losee (2001, 178-180).
} 


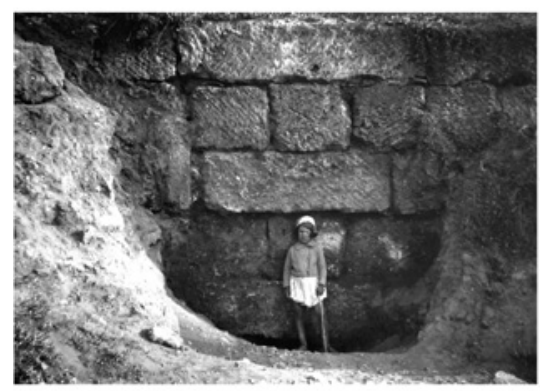

a

FIGURE 1.1 (a)A photograph from the archives of the Palestine Exploration Fund (PEF-P-166o), from a collection pertaining to Garstang's excavations at Dor (photographer unknown, 1922, courtesy of the Palestine Exploration Fund). Compare to (b) a photograph of W8424 according to the current project's recording system, identified as the north wall of the temple; Wall 2 on Garstang's plans (PHOTOGRAPH BY ISRAEL HIRSCHBERG, 1986, COURTESY OF THE TEL DOR PROJECT)

mously called the positivist view of "data" as being objective and theory-independent "the dogma of immaculate perception." 33

The analog for field recording systems is that if one rejects "the dogma of immaculate perception," ${ }^{34}$ one need not be overly hygienic about calling a spade (artifact type) a spade, or a wall a wall. To paraphrase Binford, ${ }^{35}$ we have no way of characterizing the statics without imagining the dynamics that produced them.

This ties in with another central concern for post-processualists: the denial of a single privileged (scientific) point of view. ${ }^{36}$ If one uses a form-based recording system - such as single context recording or a locus card based system, one is implicitly limiting the recording of any attribute to preplanned fields, ${ }^{37}$ each accommodating a single value. In most cases, the form would not even identify who made the observation, when, and under what circumstances. If one's persuasions are of the positivist kind, this is par for the course. There is but one correct observation for every field and-assuming it was

33 Kaplan 1998, 131-136.

34 Slaatte 1979.

35 Binford 1983, 19-30.

36 Hodder 2001, 3-5.

37 Attribute (in Archaeology): "a minimal characteristic of an artifact such that it cannot be further subdivided" (Renfrew and Bahn 2008, 578). 
made by an objective observer - the who and when do not matter. In a journalbased system, on the other hand, different log-keepers can record the same attribute or relation differently in their notebooks; and they get to elect which attributes they deem worthy of recording. The same person can even record the same observation differently in different journal entries. This should be grist for the post-processualist mill but anathema to the processualists. And yet our survey has shown that there is no correlation between the type of recording system practitioners use and the paradigm they profess. There seems to be a general trajectory toward form-based systems due mainly to the fact that there is readily available technology to support them. ${ }^{38}$

Most textbooks on methodology, such as Barker for British Archaeology, ${ }^{39}$ Joukowsky for the Near East, ${ }^{40}$ and Hole and Heizer for American Archaeology, ${ }^{41}$ seem to be explicitly or implicitly positivist/processualist in outlook. In the matter that concerns us here, they share the conviction that interpretation can and should be separated from observation. ${ }^{42}$ The field archaeologist's primary task is to objectively observe and meticulously register "the archaeological record." Interpretation has its place, but it should operate at a higher level than the primary observations. Indeed, it is only the integrity of the observation and recording that ensures the testability of propositions in whatever interpretive framework one chooses. This view is underpinned by an implicit axiom of intrinsicality-i.e., that archaeological entities (e.g., finds, contexts, deposits) have intrinsic qualities that define what they are, independent of who digs them up.

After more than twenty years of post-processualist archaeology, we have yet to see a post-processual field manual. Interpretative archaeology refers to method on some occasions, while talking about "interpretation at the trowel's edge"43 or emphasizing the importance of the area supervisor's diaries for achieving multivocality in the record. ${ }^{44}$ Yet these glimpses are no replacement for textbooks or comprehensive field manuals instructing how to plan a site, what units to use, what artifacts to collect, and how to sort and record them in the view of new theories.

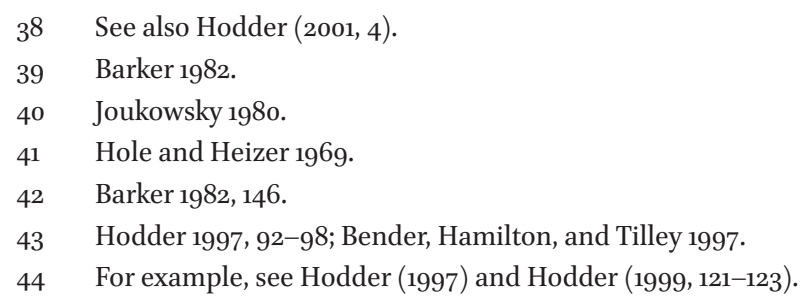


The positivist interest in the genre of methodological manuals is natural. At the bottom line, their view is prescriptive: there is a right way and a wrong way to do science. ${ }^{45}$ Instructing acolytes on the correct way is therefore the duty of those who have mastered it. Post-processual reluctance to play that game reflects an existential dilemma: "any notion of a general methodology ... could conflict with approaches which emphasize critique, interpretation and multivocality." ${ }^{\prime 6}$ Carried to its logical end, this approach means each worker gets the freedom to choose what to excavate, how to excavate it, what to keep, and how to tag it.

Few, if any, actual archaeological field projects go the full monty with their postmodern convictions. Hodder paints an idyllic picture, ${ }^{47}$ in which a laboratory specialist tours the field once or twice daily, "empowering and informing" the field team; ${ }^{48}$ a video crew is always on call to film these encounters; and a staff anthropologist critiques the interaction in real time. This is arguably possible in the rarified atmosphere of a top-percentile project of a celebrated site, in which world experts vie with each other to be included. The implementation of "methodological freedom" no doubt depends on the fact that all of these experts and most of the field staff are highly qualified professionals who have learned their craft in other-most probably positivistically orientedprojects. They thus possess a deep understanding of what is reliable and useful data and what might be the requirements of various other team members in terms of data retrieval and recording. Significantly, while Neopagans, local communities, and the world at large are invited to join the discourse about Çatalhöyük via virtual reality modeling or other so-called "experiential" techniques, it is only members of the "core group" who are allowed to "undertake ... fieldwork, research and publication."49 Moreover, their reflexive musings are recorded on top of, and not instead of, a standard codified single-context system. ${ }^{50}$

In the following sections, we propose a meta-model that supports an "agnostic" approach to field recording. ${ }^{51}$ The data recorded via this model can be successfully used by practitioners of all theoretical schools. It also is meant to

45 See Losee $\left(2001,265^{-276}\right)$ on prescriptive versus descriptive philosophies of science.

$46 \quad$ Hodder 1997, 691.

47 Hodder 1997, 691.

48 Hodder 1997, 695.

49 Hodder 1997, 698.

50 Hodder 1997, 696.

51 Meta-model: a model that describes a model. More specifically, it is a high-level abstraction that uses a modelling language to describe a model, which, itself, is defined as an external and explicit representation of a system or a part of reality. 
suit legacy data of all sorts and to ensure its compatibility with new, digitally born records. In order to do this, we have had to strip archaeological recording systems to their basics and examine their elementary components. We are also purposefully nonjudgmental. We are not asking what components a good registration system should have (a futile quest in the case of legacy systems) but what are the common components that all archaeological registration systems possess.

\section{Methodology}

\section{Definition and Basic Components of Archaeological Recording Systems}

Archaeological recording is a domain of various mixed-and-matched methods, tools, and documents. In seeking the atomic elements that all such systems share, we must first distinguish between syntactic elements and semantic entities. Syntactic elements are the components of the record itself, irrespective of what is being recorded. The most basic of these is the individual recording event. This event is a piece of content (visual, textual, numeric measurement, for example) recorded by a particular observer at a particular time and place that conveys information concerning one or more semantic entities.

That a recording system is made out of records is a bit of a "duh?" statement. Consider, however, Figure 1.1a. By itself, it is a picture of a child and a wall, and it is archaeologically meaningless. If we would add information culled from where the picture was found and (our identification of) where it was takenmetadata for this image-it becomes an observation or a recording. Note that the time and the observer are not precisely known in this case, but even their approximation has given meaning to the record.

Consider further Figure 1.2: the base of a Cypriot Monochrome vessel from the Israel Antiquities Authority's National Treasures. It is purportedly from Emmanuel Anati's excavations at Tell Abu-Hawam in 1963. On the sherd are several notations, in different ink and different handwritings. The first, probably written during or immediately after the excavation, reads " $\mathrm{N}$ wall $\mid \mathrm{s}$ square, SE corner $\mid 1.25$ to $1.80 \mathrm{om} \downarrow$ surface." Note that architectural features (N. Wall) and grid squares are used to roughly locate the find-spot, but there is no attempt to use loci as strictly bounded units. Also, the object itself lacks an identifier (ID). ${ }^{52}$ The next tagging event (in black ink) was probably the assignment

$5^{2}$ The identifier (ID) of an object is expressed in a label that consists of a combination of any alphanumeric characters attached to that object. Most data-management systems (and most archaeological recording systems, be they manual or computerized) require 


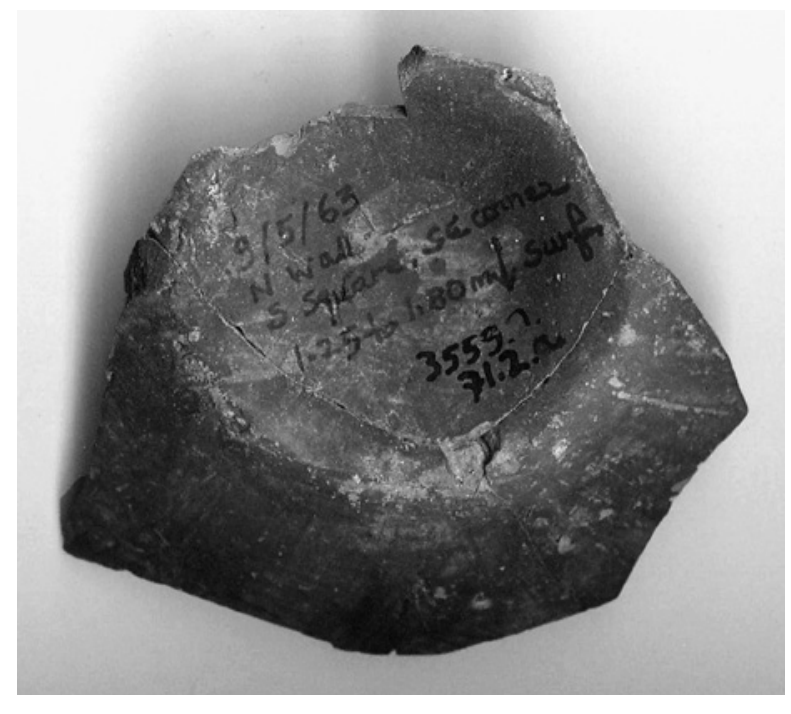

FIGURE 1.2

Base of a Cypriot Mono-

chrome vessel from the Israel

Antiquities Authority's

National Treasures, purportedly from Emanuel Anati's excavations at Tell Abu-Hawam in 1963 (PHOTOGRAPH BY SVETA MATSKEVICH, COURTESY OF THE ISRAEL ANTIQUITIES AUTHORITY AND THE DIGITAL ARCHAEOLOGY LAB)

of an inventory or collection number. The appellation 71.2 fits the format that Jacqueline Balensi used when re-cataloging the finds from Tell Abu Hawam for her PhD. ${ }^{53}$ The number 3555 (or 3559?) may be an IAA inventory number. These identifiers, too, were amended at some point with lighter additions. The most recent addition is the red dot that marks that the sherd was $3 \mathrm{D}$-scanned in the Digital Archaeology Lab in the Hebrew University, from which we obtained the image.

That someone (or at least two people, in this case) re-identified and marked the artifact may or may not be significant for our own assessment. Note, however, that in most computer-based systems today, the whole history of recording events is lost. In most systems, it is only possible to record one observation per field and correcting that field would delete the previous entry in it.

The distinction between the "recording event" and the "record" accords with the post-processual preception that an "observation" is always an interpretation made in a specific context. ${ }^{54}$ The implementation of the meta-system pro-

that any entity has a unique ID. In this volume, see a unique "ID" applied to a) texts analyzes in TEI-XML, Bigot Juloux, 165n70, and b) a database, Pagé-Perron, 204.

53 Balensi 1985 .

54 "Context" here should be taken as both the scholarly context in which the interpretation is made and the ancient context that it is made about. Calling a feature made of consolidated stone "Wall X" should be more or less automatic if one is excavating a Roman site. If the site is Paleolithic, caution would be warranted, and one would be well advised to reserve judgement. 
posed herein onto a positivistically oriented recording system may choose not to fill in the metadata (who, where, when), thus "objectifying"55 the observation into a generic record.

\section{Basic Semantic Entities in a Recording System}

The semantics of a recording system is what is being recorded, irrespective of syntax. Only two types of archaeological entities are common across the whole spectrum of existing recording methods, systems, and schools. The two mandatory pieces of information that must be recorded by an excavator in every system are a find designator and the spatial unit from which that find originated. Many systems have more than one unit of either type.

In trying to define the semantics of entities in a given system, we must consider both formal and denotational aspects of these entities. The formal facets of a spatial entity are its geometric or topological properties. The denotational facet is concerned with what it is that the abstract unit attempts to model.

\section{The Topology of Spatial Entities}

Is the unit bounded? In all contemporary registration systems that we know of, the basic spatial unit (locus, context, spit) has - at least in principle-well defined edges. So it is hard to imagine that this is not a necessary condition, or that it has not always been the case.

Like most Levantine excavators between the two World Wars, Garstang used artifact provenience designations such as "below the sand layer" and "near Wall X." ${ }^{56}$ Certain features were named or numbered, but these served as locational "hotspots" rather than as polygons with borders between them. As Figure 1.2 shows, such "impressionistic" recording systems persevered, in some cases, into the second half of the twentieth century. Indeed, even in contemporary systems non-primary spatial entities might be fuzzily defined. When referring to "Temple F" in Figure 1.1, do we mean the entire precinct or only the

55 Meta-system: data description system external to a data-management system; a system that describes a system. For positivists, the state of objectivity is the ultimate, achievable goal. They would argue that if rigorously recorded, an "observation" turns into "data." Objectifying would then mean rendering it objective. Since objective data is by definition timeless and free of point of view, the meta-data (who recorded? when? under what circumstances?) is redundant. Post-processualists either despair of ever reaching objectivity or do not believe it is desirable in the first place. For them, stripping the interpretation from its context (the metadata) "objectifies" it in the sense that it degrades the subject of interpretation to an object.

$5^{6} \quad$ For example, see Garstang (1924b). 
temple podium? The answer will probably depend on the context of the reference. As an entity, "Temple F" might not be bounded.

Are the units mutually exclusive and/or exhaustive? If this is so, then every point in (the excavated) space must belong to one and only one spatial unit. This is the case, for instance, with the set of grid squares. Note that units can be defined as exclusive but not exhaustive (for example, a coin found in the dump may legitimately have no locus).

Again, a look at higher-order units might prove revealing to those of us working in single-context or locus systems where the primary units are by default exclusive: in an attempt to clarify the term "Temple F," I might define "Precinct F" and "Podium F." Both of these are second-order or aggregate units (i.e., they can be explicitly specified as a list of [primary] loci). However, "Precinct F" would contain "Podium F." The intersection between two features in this case is not empty, and thus "feature" is a non-exclusive spatial unit.

Are units by definition contiguous? A curious feature of Kenyon's excavation at Jericho is that her layers need not be. ${ }^{57}$ If two disparate deposits, even far away from each other, were judged to originate from the same depositional event, they were given the same number, and apparently finds from them were placed in the same container (the user of the report, at least, cannot spatially differentiate between them).

\section{Denotational Classification of Basic Spatial Entities}

A spatial unit can be arbitrary, depositional, or behavioral. ${ }^{58}$ Arbitrary units are used as primary spatial designators mostly on sites that lack any architectural remains or other clear spatial features that would allow for horizontal subdivision of an excavation area and defining vertical layers. ${ }^{59}$ The standard spatial unit in most prehistoric excavations in the Levant today is the spit: a $.5 \times .5 \times .05$ $\mathrm{m}$ volume, consisting of a quarter of a $1 \mathrm{~m}^{2}$ grid square, carried down for $5 \mathrm{~cm}$. Flint finds from a spit (Fig. 1.3) receive the unique identifier (here $\mathrm{P} 28 \mathrm{~b} / 525^{-}$ $5^{20}$ ) of the basic volume unit: ( $\mathrm{P} 28$ is the grid square, quadrant $\mathrm{b}$, elevations $5^{25} 5^{20}$ ). We put these chips and chunks together in one bag because, at least initially, we wish to study them as a group. We might weigh the bag, count the number of stones in it, etc. None of these actions requires that the pieces in the bag be individuated, and it is a waste of time and effort to do so. Arbitrary units (grid squares) are often used as secondary, or higher-order, spatial designations in sites with architecture, too.

\footnotetext{
$57 \quad$ Kenyon 1981.

58 Matskevich and Sharon 2016.

59 Hole and Heizer 1969, 100-111; Roskams 2001, 212-216.
} 


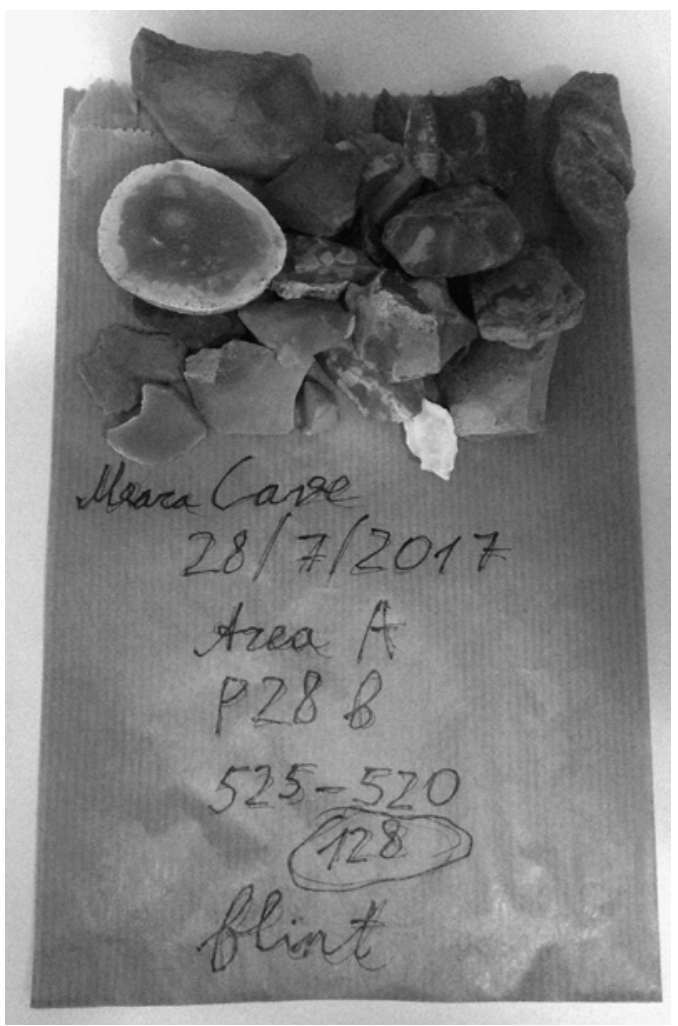

FIGURE 1.3

Flint finds from a spit ( $\mathrm{PHOTOGRAPH}$ BY SVETA MATSKEVICH)

The de facto standard definition of the "locus" in Levantine Archaeology today on sites with architecture is a contiguous segment of the site volume interpreted as being the result of a single depositional event. This is what we call the depositional denotation of the locus. ${ }^{60}$

This was not always the case, however. The classic "Locus to Stratum" model initially defined the "locus" as an architectural space (Fig. 1.4). ${ }^{61}$ Features other than rooms (e.g., tombs, pits, and installations) often obtained "locus" designations as well; but the denotation of a "locus" under this system is always a space within which some specific human activity took place. It is thus a unit of (ancient) behavior, according to the interpretation of the excavator. Among the

\footnotetext{
$60 \quad$ Sharon 1995a, 22-23.

61 Stratum: a single construction-destruction cycle within a stratified sequence of deposits that form a multi-layered site (e.g., tell). About the "Locus to Stratum" model, see Lamon and Shipton (1939, xxiii-xxiv). Some rooms on this plan have a locus number, but open spaces and areas where the architecture is not well preserved typically do not. Walls, floors, pits, and installations are drawn but not numbered.
} 


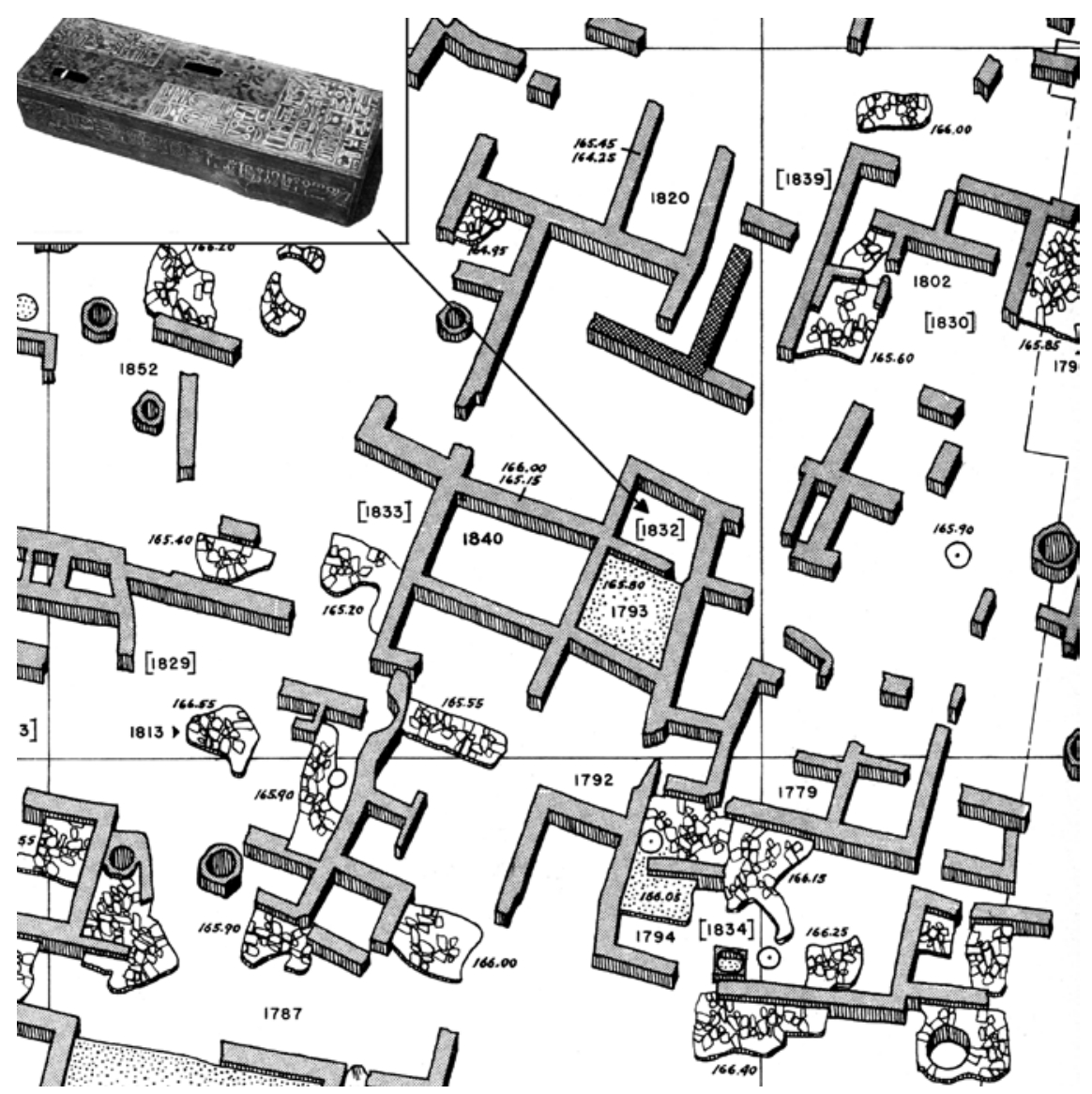

FIGURE 1.4 Megiddo, Area cC, part of the Stratum VIIB and VIIA plan (Loud 1948, fig. 409)

most famous examples of employing these units are excavations at Beersheba, ${ }^{62}$ Tell Jemmeh, ${ }^{63}$ and to some extent Megiddo of Yigael Yadin. ${ }^{64}$

Tracing the paths by which the "locus" evolved from a behavioral unit to a depositional one in the archaeology of the Near East is complicated by the fact that excavators rarely explicitly defined their units, or even acknowledged that their "loci" are different from those of their predecessors. This issue, however, is outside of our scope. Suffice it to say that there is no direct influence between this evolution and that of the "context" in British and European archaeology, although the result is similar. It has been claimed that depositional units

\footnotetext{
62 Aharoni et al. 1973, 119-120.

63 Van Beek 1988, 158.

64 Zarzecki-Peleg 2016.
} 
are observational, ${ }^{65}$ while behavioral ones are interpretational, and hence that the former are "scientific" while the latter are not. This is patently untrue. What constitutes an "event" within the depositional process is strictly in the eyes of the beholder. Indeed, our continued involvement with micromorphologists on the tell teaches us that each depositional "event" can be broken into subevents, ${ }^{66}$ all the way down to the molecular level.

There is, however, one way in which depositional units can be seen as more basic than behavioral ones. An implementation where the basic volume unit is depositional can define features (behavioral units) as higher-order entities. In as much as the construction and use of a feature will result in the deposition of at least one (positive or negative) layer, ${ }^{67}$ it can be defined as an aggregate of at least one but usually more primary depositional units.

\section{Semantics of the "Find"}

It seems self-evident that any archaeological registration system needs an entity to model, identify, and tag the artifacts and ecofacts that are found. ${ }^{68} \mathrm{How}$ ever, as more and more classes of items are being studied in Archaeology, defining what constitutes a "find" proves to be less straightforward than it might seem.

In addition to the individual find, many systems also have ways of tagging batches of objects. Such is the "basket" in many tell excavations (reminiscent of the old days when potsherds from the locus were collected in wicker basketsnowadays usually plastic buckets). Similarly, most prehistoric excavations in the Levant would individually save flint tools, tagging each of them with its exact coordinates, but keep all the debitage from the spit together in one bag (Fig. 1.3).

In our quest for primitives, however, we ask: which of these entities can be considered a special case of the other? Somewhat counterintuitively, we contend that it is the batch and not the artifact that constitutes the basic unit of "finding." ${ }^{69}$ An (individual) object is merely a sample of size one. Note also that

65 For example, Chapman 1986.

66 Shahack-Gross et al. 2005; Shahack-Gross 2011.

67 Layer (in Archaeology): a unit of sediments in a stratified archaeological site, created as a result of one of the site-formation cycles. "Negative" layers are the result of the removal of sediment (for example, the outlines of a pit would represent a negative layer, while the sediment within the pit would be called a layer).

68 Ecofact: non-artifactual organic (botanical or biological) or inorganic (resulting from geological processes) object recovered from an archaeological context.

69 Batch: a group of items dealt with at the same time or considered similar in type 
for many types of finds (such as a sediment sample) the "count" attribute is simply irrelevant. The sample size in such cases might be weight, or some other attribute.

There are often cases in the archaeological workflow that require the reidentification of, for example, an artifact, ecofact, or batch. The potsherd in Figure 1.2 was apparently not given a unique identifier in the excavation (unless the whole story written on it is considered its ID). Later events in its life history (including cataloging and storage) had-literally, in this case-left their mark by giving it different numbers.

Another usual case is sub-sampling from a batch. Consider the bag of debitage in Figure 1.3. Suppose we happen to choose two chunks from this bag for a provenience study of a random sample of the raw materials on site. As these two particular pieces will now each be subject to a battery of tests, they need to be individually named. A similar case might occur if we split an olive pit and sent the two halves to two different radiocarbon laboratories for an inter-calibration study. What was once an ecofact is now two ecofacts, which will have two different (hopefully similar) records in our registration system.

The opposite case can also be found: a new aggregate entity that is different from the set of its parts. Mending or refitting, for instance, can create a "find" that will need to be recorded in its own right. This new object, however, may be made of several different objects, possibly from different find-spots. A somewhat extreme case is illustrated in Figure 1.5. In 2004, S. Rebecca Martin managed to refit a fifth-century red-figure krater sherd found in Stern's excavation at Dor in 1993 (Dor Area F, L8605, Reg. no. 85234) with another piece found in Garstang's excavation in 1923-1924 (Reg. no. P 2875). Note the mending hole that indicates the pot was already broken in antiquity. Martin also identified the scene: Heracles in the Garden of the Hesperides. This would not have been possible based on either piece alone. ${ }^{70}$ Thus the aggregate entity has additional attributes, over and above those of its individual constituents.

Even the differentiation between a spatial unit and a "find" is less trivial than it might seem at first glance. Consider the case of a rock-cut olive press versus a portable one. The rock-cut installation would probably be recorded as a spatial unit, because it has fixed coordinates and it is the context for olive pits found on its surface. A portable press, on the other hand, could be taken out of its context. Therefore, it would probably be treated as an artifact. It would get a find ID and possibly be moved to a museum or artifact storage space.

(Cambridge Dictionary, s.v. "batch," <http://dictionary.cambridge.org/dictionary/english/ batch $>$ [accessed June 20, 2017]). 


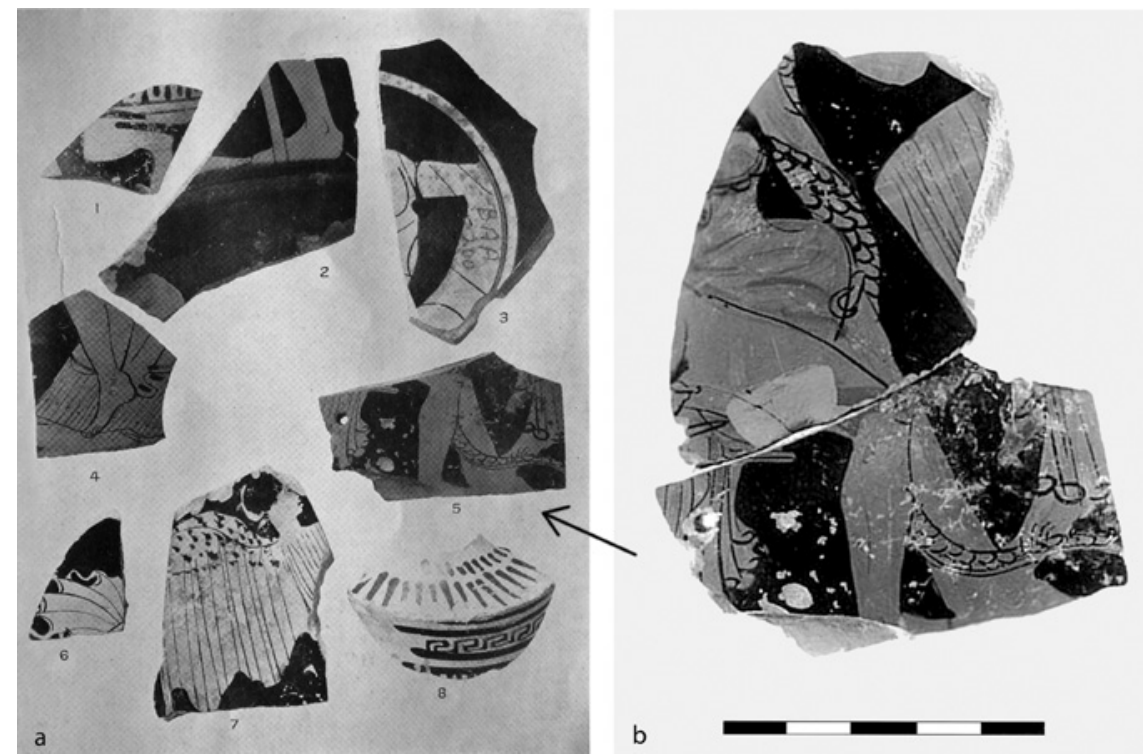

FIGURE 1.5 (a) Attic red-figure sherds from Garstang's excavation (Iliffe 1933, pl. 7b:5) (b) The refitted sherds (Stewart and Martin 2005, fig. 4; PHOTOGRAPH BY GABI LARON, COURTESY OF THE ISRAEL ANTIQUITIES AUTHORITY)

To deal with these conceptual difficulties, we propose that the ontological order between signifier (the tag) and signified (the find) be reversed. The basic entity in the recording system is not the "find" but the "sampling event" (or perhaps more specifically, the "tagging event"). This definition has considerable conceptual impact. There is no intrinsic property that defines a "find." Rather, it is the fact that the archaeologist picked out some "stuff" from the archaeological record and tagged it for further study. All other permutationsthe sub-sampling of a sample, the retagging of an artifact with a different identifier, etc. — can be described as further tagging events. These can be connected (and possibly inherit attributes, such as the find's original context) from previous events in the workflow; but they remain distinct. The tag should be thought of not as a permanent identifier to a persistent object but as a bill of lading that facilitates the archaeological workflow.

That the most basic ingredients of archaeological registration are "events" the "recording event" and the "tagging event" — emphasizes how early in the archaeological process interpretation starts: not during report-writing or discussions of the dig but the moment something is picked out of the ground. The raw data of an excavation is a collection of interpretations fixed in pre-printed forms, diaries, and tables. The beginning of the existence of an archaeological record is not the freezing of "cultural dynamics" into fossil "statics" but the act 
of recording "stuff" on the excavation. This is not to say, of course, that the ancients had no impact on the formation of an "archaeological record" but that it is a co-production of ancient societies and modern archaeologists.

\section{Semantic Modeling and Mapping of the Recording Systems}

Conceptual Reference Models for Archaeological Field Recording The CIDOc Conceptual Reference Model (CIDOC CRM) ${ }^{71}$ is a leading standard (ISO 21127/2006) ${ }^{72}$ for conceptual referencing of cultural heritage data. ${ }^{73}$ Developed in the last decade by one of the special-interest groups of ICOMOs for museums and object collections, ${ }^{74}$ it gained popularity in other domains of the humanities and cultural heritage.

The CIDOC CRM was first adopted into the archaeological domain by English Heritage. After some adaptations and additions (the modified version was dubbed CRM-EH), they successfully mapped their field recording systems. ${ }^{75}$ Due to the standard's growing popularity, the initial group of researchers developed several extensions of the basic CRM, aiming at incorporating additional information about the objects, such as bibliographic references, provenience, and other scientific analyses, as well as spatio-temporal models. The archaeological fieldwork extension, CRMarchaeo ${ }^{76}$ accommodates stratigraphy-related concepts that were missing from CIDOC CRM.

A Conceptual Reference Model is a lingua franca of recording systems, and the main purpose of ontological mapping is to ensure compatibility of the terminologies used by various data-management systems, which is one of the necessary conditions for creating Linked Open Data clouds. ${ }^{77}$

$71 \quad$ Conceptual Reference Model (CRM): provides definitions and a formal structure for describing the implicit and explicit concepts and relationships within a system (IGI Global Dictionary, s.v. "Conceptual Reference Model," <https://www.igi-global.com/dic tionary/conceptual-reference-model-crm/5242> [accessed June 20, 2017]). For further discussion, see in this volume, a) Eraslan (299-300), who suggests using CIDOC CRM for features' vector and semantic schemes; b) Nurmikko-Fuller (353-354), who suggests improving online publishing of cuneiform and photography with CIDOC CRM classes.

72 Iso stands for International Organization for Standardization, which is a non-governmental body that develops and publishes international standards of products, services, and systems.

73 Doerr 2003; Doerr, Schaller, and Theodoridou 2010.

74 International Council on Monuments and Sites (ICOMOs), <https://www.icomos.org/ en/> (accessed June 20, 2017).

75 Cripps et al. 2004.

76 CRMarchaeo, CIDOC CRM website, <http://www.cidoc-crm.org/crmarchaeo/home-3> (accessed June 18, 2017).

77 Isaksen et al. 2010; May et al. 2012. For further information on Linked Open Data, see in this volume, Nurmikko-Fuller, 344 . 


\section{S KOs Format for Controlled Vocabularies}

The Simple Knowledge Organization System (skos) ${ }^{78}$ is a model for expressing vocabularies, thesauri, and taxonomies in a machine-readable format, namely the Resource Description Framework (RDF). ${ }^{79}$ SkOs is a World Wide Web Consortium (W3C) standard employed for over a decade for linking data in the Semantic Web.

Controlled vocabularies and taxonomies are essential for efficient data retrieval in archaeological practice in general, and in field recording in particular. Presented in skos format, they can be integrated into the Linked Data cloud to serve all participant datasets.

\section{Graph Databases}

In a graph model, the data are structured so that each entity (subject), ${ }^{80}$ its attribute (object), and the relationships between them (predicate) create a triple. ${ }^{81}$ The triples are linked via entities and attributes into a triple store. ${ }^{82}$ The main advantage of the graph model is its flexibility, which allows for querying large datasets by setting relations as query criteria. The second and third generations of the www intensively use triple storage (RDF format) as a data representation model.

78 Simple Knowledge Organization System (skos): "an area of work developing specifications and standards to support the use of knowledge organization systems (KOS), such as thesauri, classification schemes, subject heading systems, and taxonomies within the framework of the Semantic Web" (skos home page, w3C, <https://www.w3.org/2004/o2/ skos/> [accessed June 20, 2017]). On other languages that are easily machine-readable (or machine-actionable), see in this volume, Bigot Juloux, 163-164; Pagé-Perron, 200; Nurmikko-Fuller, 336, 339-340.

79 For further information in this volume, especially for online publishing, see NurmikkoFuller, 338-340, 343-344, 352, 36o.

80 Graph model: a model that describes relations between objects as a collection of nodes connected by edges; graphs are studied and explained by graph theory ("Graphs and Networks," Mathigon, <https://mathigon.org/course/graphs-and-networks> [accessed June 20, 2017]). For further information on Graph Theory, see in this volume, Ramazzotti, $66 \mathrm{n} 24,67 \mathrm{n} 28,73$.

81 Triple: a semantic statement that consists of three parts: subject, predicate (property), and object. The statement "Floor A reaches Wall B" is a (stratigraphic) triple. For further explanation of the triple in this volume, see a) Nurmikko-Fuller, $345^{-347}$, for online publishing, and b) Pagé-Perron (202-203), who uses triples for network graph.

82 Triple store: a database for the storage and retrieval of triples; see Curé and Blin (2015). 
In a graph database any entity may be connected to any other. ${ }^{83}$ It is up to the individual application to determine if such a connection makes sense. This is not usually the case in conventional relational databases, where relationships between entities are predetermined by the schema. ${ }^{84}$

Following other domains, Linked Data (LD) initiatives in archaeology worldwide use interlinked RDF data stores to create cross-searchable platforms of geographical, historical, and archaeological data. ${ }^{85}$ Among the most successful projects are Europeana, Pelagios, and Nomisma. ${ }^{86}$

The major challenges of making archaeological data available on the web in a format that can be referenced from other resources are mapping the datasets to an ontology and converting data from various databases to RDF format. ${ }^{87}$ These issues were addressed in a step-by-step process by the team of scholars from the Hypermedia Research Unit at the University of Glamorgan. ${ }^{88}$ The STAR and STELLAR projects developed a set of tools that simplify the process of preparing data to be semantically linked. ${ }^{89}$ We used the STELLAR.Console util-

83 Graph database: see graph model. For a graph data structure in the context of text analysis, see in this volume, Pagé-Perron, 196-197, 198 fig. 6.1, 202, 219.

84 Relational database: a computer database in which data are organized in tables, where each table contains all the instances of one entity. Each "tuple" (meaning an ordered list or row) in a table represents one instance of the entity and must have a unique identifier as one of its attributes; the columns (fields) of the table represent all other attributes of the entity, including keys of related entities. The relationships between tables are defined as links between keys. The database schema describes the structure of the database (tables, attributes, and keys) in a formal language supported by the Database Management System (DBMS), software that enables an administrator to create and manage databases and to monitor, modify, and analyze their interactions with users and other applications. See also in this volume, Pagé-Perron, 196, 202, 204.

85 For further information on LD, see in this volume, Nurmikko-Fuller, 340, 344.

86 Europeana: www.europeana.eu/portal/en; Pelagios: <http://commons.pelagios.org/>; Nomisma: <http://nomisma.org/>. All accessed June 18, 2017.

87 Ontology (in data sharing): the formal conceptualization of a particular domain that is shared by a group of practitioners of that domain (Maedche 2002, xv). For additional information, see in this volume, a) in the philological field, Bigot Juloux, 165-181, and Prosser, 320-322; b) applied to online publishing, Nurmikko-Fuller, 343, 348-350, 353360.

88 Now part of the University of South Wales. Hypermedia Research Unit, University of South Wales, <http://hypermedia.research.southwales.ac.uk/> (accessed June 20, 2017).

89 Binding et al. 2008; May et al. 2012; "Semantic Technologies for Archaeological Resources" (STAR), Hypermedia Research Unit, University of South Wales, <http://hypermedia. research.southwales.ac.uk/kos/star/> (accessed June 18, 2017); "Semantic Technologies Enhancing Links and Linked data for Archaeological Resources" (stelLAR), Hypermedia Research Unit, University of South Wales, <http://hypermedia.research.southwales. ac.uk/kos/stellar/> (accessed June 18, 2017). 
ity at all stages of the presented study and wish to express our gratitude to its authors. ${ }^{90}$

\section{Selected Issues in Data Integration}

\section{Modeling and Linking Legacy Data}

Samples of the Dor datasets described above, from the excavation of the tell and from underwater explorations around the tell, were linked using a twostep procedure: skosifying their terminologies and mapping the data models to CIDOC CRM. ${ }^{91}$

The first stage is meant to create a common platform for the terminologies used by the two teams. The problem was not only the differences in the terms used to define excavation and interpretation units, but also the fact that the terminologies overlapped. The same terms denote different concepts in the two systems. For instance, on the terrestrial excavation at Dor, and most excavations in the Levant today, an archaeological site is an accumulation of archaeological remains spatially related to each other, and an area is a subdivision of the site (usually several contiguous grid squares, encompassing at least one, possibly several, architectural features). In Raban's terminology, "site" is an extent of excavation that encompasses previously identified large-scale architectural features, exposed (at least partly) by erosion of the tell slopes and shifting sands at the beach or bottom of the bay (for example, "Southern Quay" or "Purple-dye Factory"). Conceptually, this term is equivalent to "area" on the tell. Moreover, rather than any sort of open-area excavation, Raban usually dug small-scale probes in specific points of these large-scale features, such as the corner between two walls, straightening a sea-cut section, etc. Each of these was called an "area." There is no equivalent unit in the terrestrial excavation.

The term "locus" presents a more challenging problem in the data-integration effort. In both recording systems, locus is the basic excavation unit. In the terrestrial excavation, the locus is contiguous, bounded, exclusive, and exhaustive and models a depositional unit. ${ }^{92}$ Raban never defined what he calls a "locus," but from his records it seems that the same term was used to describe

$90 \quad$ "STELlar Applications," Hypermedia Research Unit, University of South Wales, <http:// hypermedia.research.southwales.ac.uk/resources/STELLAR-applications/> (accessed June 18, 2017).

91 skosifying: a process of mapping user-defined terminology (thesaurus or vocabulary) to sкos. See also in this volume, Nurmikko-Fuller, 353-354. Data model: an abstract model that describes the data structure and relations within a system, where the data is stored, and how it is processed. See also in this volume, Prosser $319-320$. 
a vaguely defined location within an area, often (but not always) bounded by architectural remains or natural features, sometimes identified as loci and sometimes not (i.e., not exhaustive). Therefore, several "terrestrial loci" might comprise one "maritime locus". Nevertheless, in both cases these are the basic unit of excavation. This means that in practical terms there is little we can do about their incompatibility. For instance, comparing ceramic assemblages from loci from the different recording systems is potentially misleading, but since no smaller subdivisions exist, there is little we can do except note the problem. The conceptual cross-referencing of these terms as equivalent would be incorrect. Mapping both types of loci to the Basic Volume Unit (BVU) ${ }^{93}$ entity of the reference model and expressing their difference through their properties can at least make the user aware of their characteristics.

\section{Mapping Ambiguities}

While we have enough trouble with various terms used to define spatial units of excavation, there are more complex cases to handle.

Let us return to the case of the rock-cut vs. portable olive presses. In a tablebased database, ${ }^{94}$ these objects will end up in different tables, the first one as a spatial unit, and the second as a find. Each will be recorded in a different set of forms, and there is (usually) no single query, in which both olive presses can be retrieved. The combined flexibility of an event-driven (rather than a persistent-item) registration system and a graph database can provide a partial solution. Both BVU-s and the finds will be parts of the data cloud, ${ }^{95}$ therefore they could be queried together. The other part of the solution is using one united thesaurus of terms for various value lists within the database. A search for the "olive press" entry anywhere in the database will return both contexts and finds that contain this value in one of the description fields (Fig. 1.6).

\section{Modeling Multivocality}

This leads us to another feature that can be handled in a graph data model, namely the multivocality of the archaeological record. The term "multivocality" is used in different theoretical approaches within the discipline or as various layers of perception in communicating archaeology to the public. ${ }^{96}$ In this

93 Basic Volume Unit (BVU): the primary excavation unit of a recording system, defined arbitrarily (grid square), stratigraphically (locus, context), or behaviorally (feature).

94 Table-based database: see relational database (note 84, above).

95 Data cloud: visualization diagram for a triple store or multiple graph datasets in the Linked Open Data initiative.

96 See, for example, Habu, Fawcett, and Matsunaga (2008). 

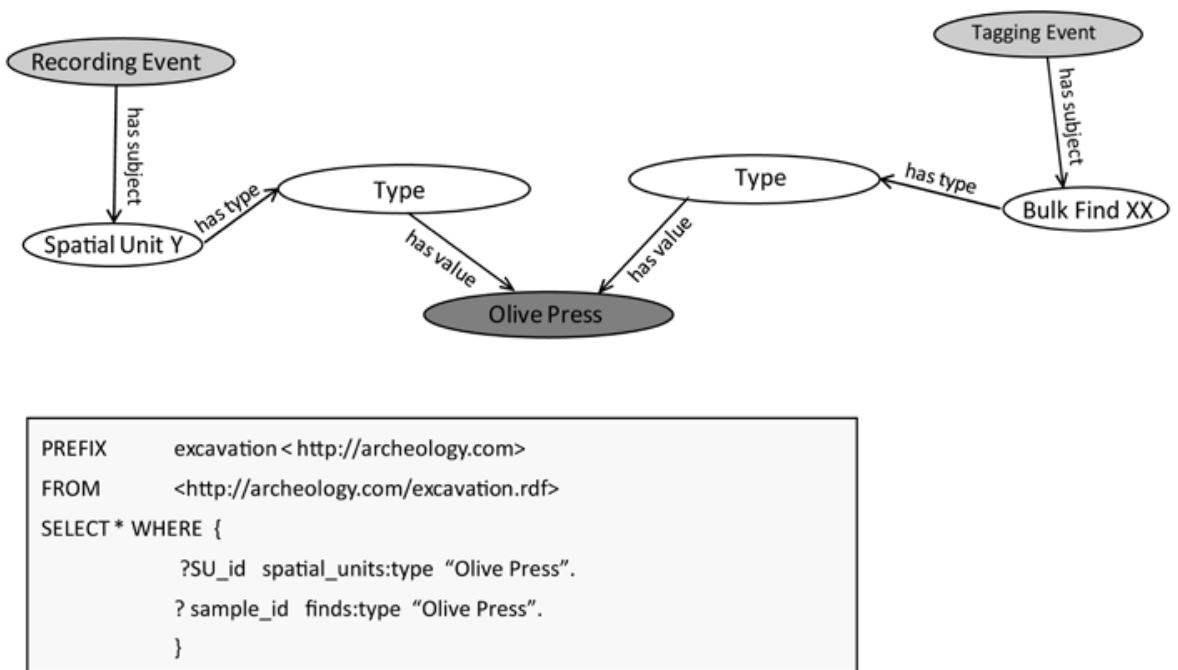

FIGURE 1.6 Modeling ambiguities

context, however, multivocality is meant as pluralism in the very basis of archaeological process, the initial interpretation of the excavated matter.

Multiple opinions at this level result both from the fact that today archaeology is a team effort, not the one-man shows of nineteenth- and early-twentieth-century projects, and from the constantly growing timespan between the excavation and the publication, which allows for repeated analysis of the finds, using various methods that bring inconsistent results. In the proposed metasystem, there can be (and usually are) multiple recording events to any entity. This means that every attribute assigned to every entity within excavation dataset (except the entity ID) has a timestamp and authorship. This approach allows values to be added to any of these attributes by different people at different times. If today a find dated to the Persian period turns out to be Hellenistic, ${ }^{97}$ the first dating need not be deleted and overwritten (although it would be connected to the subsequent "dating event" so a timeline of evolving interpretation can be established). The new interpretation would be added, and the old one would be kept, because it is part of the knowledge-creation process.

In a graph database, the implementation of this approach is as simple as adding two properties to each attribute, without any changes in the data

97 Persian period (in the Levant): 539-334 BCE. Hellenistic period (in the Levant): 333 BCE$63 / 57$ BCE. 
structure or alterations in the existing records. Since we do not propose here the actual replacement of all relational databases with graphs but suggest using a graph database as a conceptual model only, the solution for pluralistic records can be only a partial one. By default, relational databases can only support one attribute per field and one-to-many relationships between tables. So multiple relationships between attributes can only be implemented where the underlying schema has been specifically restructured to allow for multiple values and many-to-many relationships (either for all attributes in all tables or for specific attributes in some tables). Other NosQL solutions, ${ }^{98}$ such as document-oriented databases, ${ }^{99}$ have a more abstract structure that allows for flexibility in the implementation of the underlying storage for graph databases. They also often enable more efficient data retrieval and easier partitioning of large volumes of data.

Keeping track of various interpretations can be important, because in a domino effect they influence our understanding of similar objects/features found later, as well as the next stages of interpretation of related findings. An example is shown in Figure 1.7. Fragments of large terracotta masks were found in several different Persian period loci in Area D at Dor in the 199o's. Ephraim Stern had several of these fragments reconstructed as a Gorgon antefix-a common architectural element in Archaic Greek temples. ${ }^{100}$ Based on this reconstruction, he argued for the existence of a Greek-style temple in Area D or nearby, and for the existence of a Greek community at Dor at that time. Contrary to this reconstruction and interpretation, Martin maintains: ${ }^{101}$ (a) This tile is reconstructed from several non-contiguous fragments. We do not know that it would have looked like that, or even that all of these fragments were from the same original object. (b) The tile lacks the peg that fixes the antefix to the architecture behind it. (c) Terracotta antefixes form (a small) part of an assemblage of simpler terracotta tiling elements in the roofs of Greek temples. The latter are missing at Dor. Had there been a Greek-style temple at Dor, we would have found many simple tiles per each decorated one. (d) There is a long tradition of Phoenician cultic masks (albeit in a different style from these). She

98 NosQL: Database models that utilize a non-tabular or not only tabular data structure. Examples include a document store (such as XML), triple store (RDF), graph databases, and object-oriented databases.

Document-oriented database: a data store, the main concept of which is the document. Documents can be organized hierarchically, grouped into collections by some criteria, or tagged. Entities in a document store do not necessarily share a structure; differently structured documents can be stored in the same database. 
sees this mask as the appropriation of a well-known Greek style by the local (Phoenician) population, for use on a local artifact type. There is minimal evidence, according to Martin, for any Greeks actually residing at Dor. Without endorsing either of these views, we maintain that such debates are fruitful and indeed essential to the evolution of the discipline. Registration systems should encourage such multivocality.

In other cases, an excavator might base his or her decision about dating, function, and other characteristics of a context on a single especially indicative object, while others might claim that the object's relation to the context was doubtful. Note locus [1832] in Figure 1.4: (the square brackets denote that it belongs to VIIB, according to the excavators). This is the find-spot of the bronze base of statue Ramesses VI, a main chronological peg for the dating the end of the Bronze Age in the Levant. According to the excavator, it was found "under a wall in stratum VIIB room $183^{2}$ as if deliberately buried there and therefore intrusive"102 (note that the context has no locus identifier; it is spatially defined relative to features in the stratum above). However, the excavators of Megiddo believed, along with most of the archaeological community at the time, that the Late Bronze Age ended with Merneptah, half a century before, and that Stratum VII was still the Bronze Age. They were well aware that this object undermined the chronological scheme that they favored, but they did not really provide any evidence for its intrusiveness. Later scholars have used this particular find, and its findplace, to argue that the end of the Bronze Age in the Levant should be lowered by about 50 to 75 years. ${ }^{103}$ Our contention here is that while data-consistency checks built into the registration system might be used to flag such anomalies as a find whose intrinsic date conflicts with that of the context in which it was found, they should nevertheless allow these anomalies to be retained. Erroneus (or at least seemingly discordant) observations can be as conducive to research as concordant ones.

\section{Modeling Uncertainties}

Even more common than multiple opinions are the cases in which there is a single indecisive perspective. A wall is possibly dovetailed with another wall, but maybe one abuts the other; a ceramic vessel rim fragment might belong to a jar or to a jug; a ceramic petrographical sample, the provenience of which could be Cyprus or Lebanon, and so on. Uncertainties are present at all stages of interpretations and in all attributes of the entities and relations between them. On the data-management level, this means that question marks should

102 Loud 1948, 135.

103 Finkelstein 1995, 213-239. 


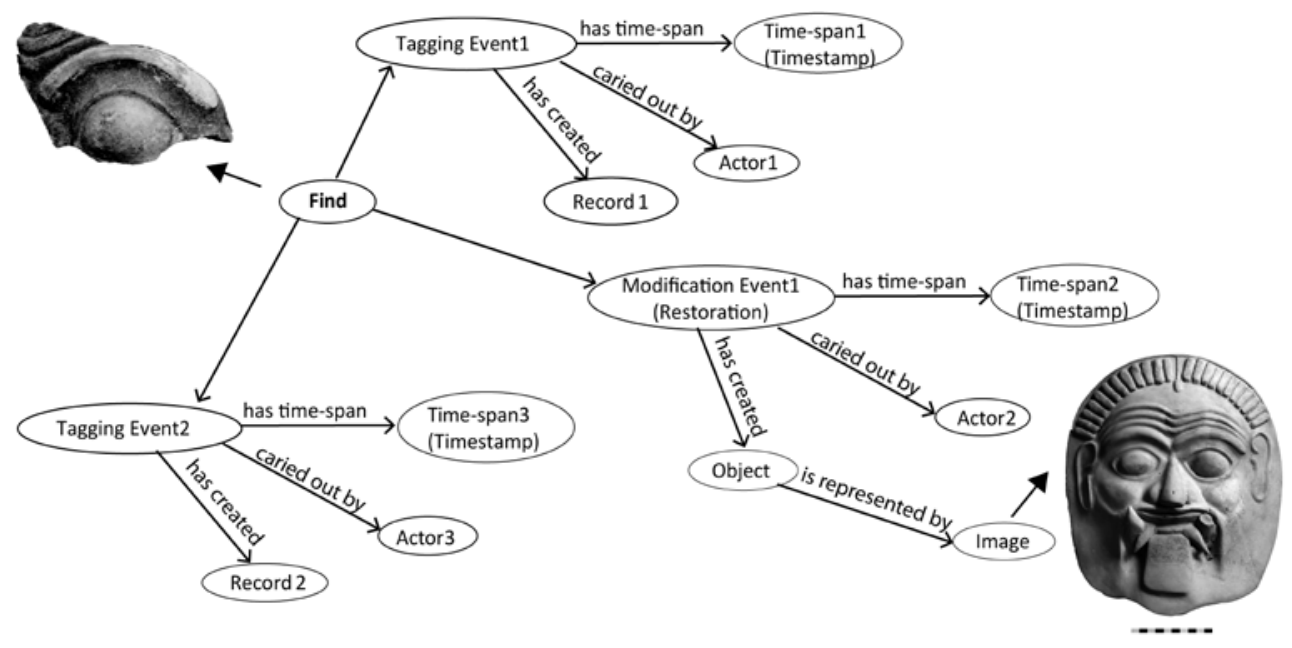

FIGURE 1.7 Modeling multiple interpretations of one find

be allowed in every piece of recorded data to register the fact that there were doubts.

It often happens that even when no new data confirms an interpretation, the initial question marks disappear on the way from the raw data to the report. According to Barker, ${ }^{104}$ as part of a "high-level" interpretation process, doubts should be removed from the final report in order to avoid presenting too much information. ${ }^{105}$ On the contrary, it can be argued that revealing all doubts to a report reader is a matter of professional ethics and no less important than compiling a convincing story. The history of this debate goes back to the late nineteenth century in England and two major figures on the archaeological scene: General Pitt-Rivers and Sir Flinders Petrie. Pitt-Rivers claimed that all information is objective; therefore, he believed everything should be recorded and published. ${ }^{106}$ Petrie accepted the presence of uncertainties, but he was convinced that doubts and queries were "worth nothing in themselves"107 and that an excavator should decide in the field what information should be recorded as reliable facts. The rest should be omitted completely (including discarding finds).

\footnotetext{
104 Barker 1982.

105 See the discussion of Barker's ideas in Hodder (1997, 692-693).

106 Pitt-Rivers 1887, xvii.

107 Petrie 1904, 50.
} 

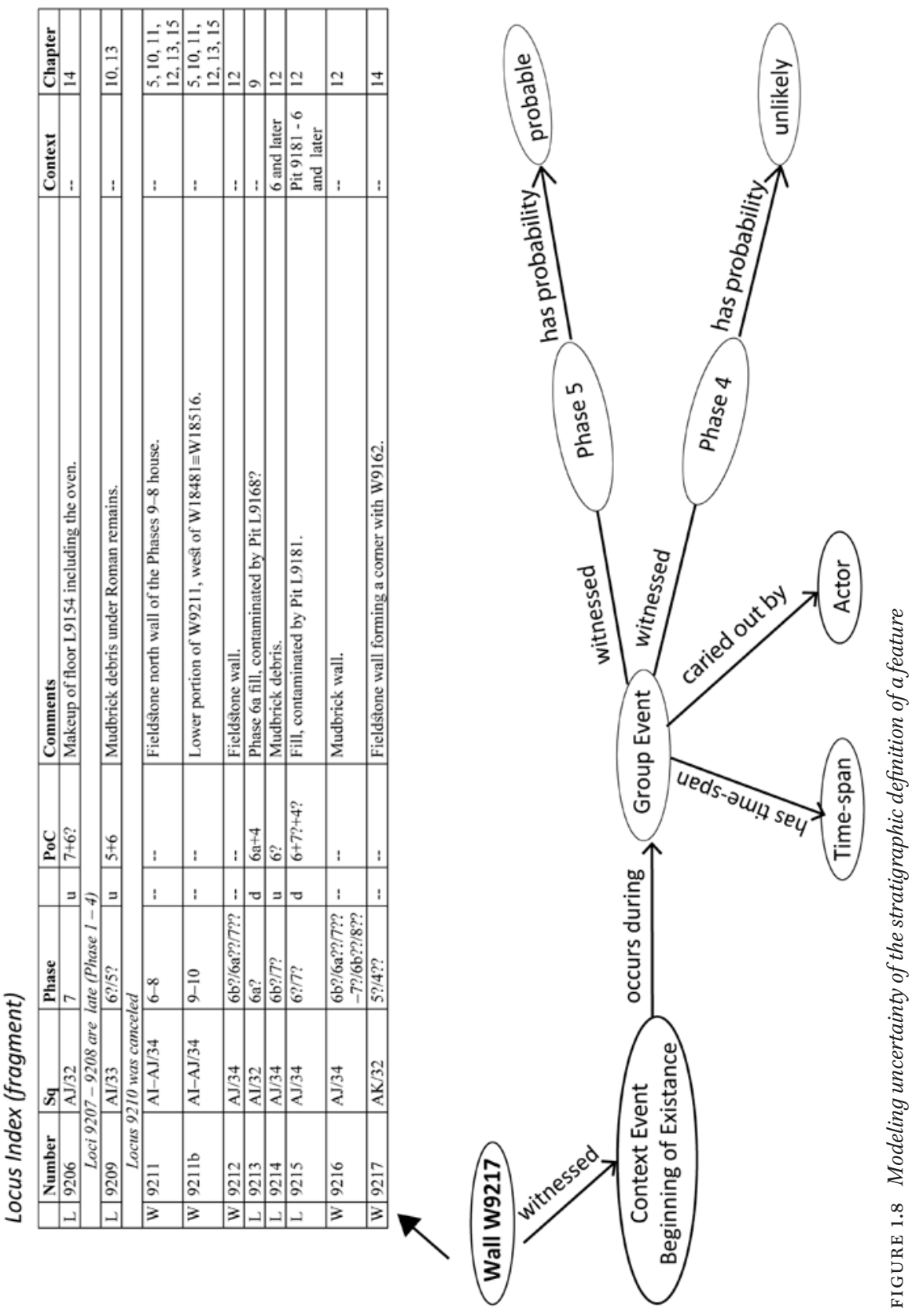
Back to field records, very often it would be extremely valuable to know how certain the author was about each of his or her assumptions, i.e., could the level of uncertainty be expressed in one, two, three, or more question marks or expressions indicating "almost sure," "likely," "very unlikely," etc. The problem of data uncertainty in archaeology is dealt with in the context of computerized data modeling, ${ }^{108}$ GIS, ${ }^{109}$ and virtual reconstructions, ${ }^{110}$ but it is barely addressed in the Linked Data projects. ${ }^{111}$

In a graph database, the grading of uncertainty can be implemented as a property of the relation between entities. Thus, everything in the data cloud (again, except of the entity ID) can be "tagged" to tell a user about the author's attitude toward her own theory (Fig. 1.8).

Recording the levels of uncertainty allows for per-record or even per-property evaluation of the data. In stratigraphic analysis, which typically operates only with the records, because the excavation units are gone, such qualifications could be invaluable. A dataset can be filtered by this property to show "probable" or only "very likely" scenarios. Finally, a methodological study might find it interesting to trace the dynamics of the levels of uncertainties during the excavation campaigns, between the team members, or in relation to specific topics.

\section{References}

Aharoni, Yohanan, Zeev Herzog, Moshe Kochavi, Shmuel Moshkovitz, and Anson F. Rainey. 1973. "Methods of Recording and Documenting." In Beer-Sheba I:Excavations at Tel Beer-Sheba, 1969-1971 Seasons, edited by Yohanan Aharoni, 119-132. Publications of the Institute of Archaeology. Tel Aviv: Tel Aviv University.

Balensi, Jacqueline. 1985. "Revising Tell Abu Hawam." BASOR 257: 65-75.

Barker, Philip. 1982. Techniques of Archaeological Excavation. 2nd ed. London: B.T. Batsford.

Bender, Barbara, Sue Hamilton, and Christopher Tilley. 1997. "Leskernick: Stone Worlds; Alternative Narratives; Nested Landscapes." Proceedings of the Prehistoric Society 63: $147^{-178 .}$

108 Computerized data modeling: the process of creating a digital data model; see Brouwer Burg, Peeters, and Livis, eds. (2016).

109 Lawrence, Bradbury, and Dunford 2012.

110 Danielová, Kumke, and Peters 2016.

111 But see Isaksen et al. 2010. 
Binding, Ceri, Keith May, and Doug Tudhope. 2008. "Semantic Interoperability in Archaeological Datasets: Data Mapping and Extraction via the CIDOC CRM." In Proceedings (ECDL 2008) 12th European Conference on Research and Advanced Technology for Digital Libraries, Aarhus, edited by Birte Christensen-Dalsgaard, Donatella Castelli, Bolette Ammitzbøll Jurik, and Joan Lippincott, 280-29o. Berlin: Springer.

Binford, Lewis R. 1962. "Archeology as Anthropology." AmAnt 28: 217-225.

Binford, Lewis R. 1968. "Archeological Perspectives." In New Perspectives in Archeology, edited by Sally R. Binford and Lewis R. Binford, 5-32. Chicago: Aldine.

Binford, Lewis R. 1977. "General Introduction." In For Theory Building in Archaeology: Essays on Faunal Remains, Aquatic Resources, Spatial Analysis, and Systemic Modeling, edited by Lewis R. Binford, 1-10. New York: Academic Press.

Binford, Lewis R. 1983. In Pursuit of the Past:Decoding the Archaeological Record. London: Thames \& Hudson.

Brouwer Burg, Marieka, Hans Peeters, and William A. Lovis, eds. 2016. Uncertainty and Sensitivity Analysis in Archaeological Computational Modeling. Interdisciplinary Contributions to Archaeology. Cham: Springer International.

Chapman, Rupert L. 1986. "Excavation Techniques and Recording Systems: A Theoretical Study." PEQ 118: 5-26.

Clarke, David. 1973. "Archaeology: The Loss of Innocence." Antiquity 185: 6-18.

Cripps, Paul, Anne Greenhalgh, Dave Fellows, Keith May, and David Robinson. 2004. "Ontological Modelling of the Work of the Centre for Archaeology." CIDOc CRM Technical Paper. <https://www.semanticscholar.org/paper/Ontological-Modelling-of-the-workof-the-Centre-for-Cripps-Greenhalgh/0245f5f4caoboa45od5c568314bgbf5641b6o371>.

Curé, Olivier, and Guillaume Blin. 2015. RDF Database Systems:Triples Storage and SPARQL Query Processing. Amsterdam: Morgan Kaufmann.

Danielová, Mariana, Holger Kumke, and Stefan Peters. 2016. "3D Reconstruction and Uncertainty Modelling Using Fuzzy Logic of Archaeological Structures: Applied to the Temple of Diana in Nemi, Italy." Cartographica: The International Journal for Geographic Information and Geovisualization 51 (3): 137-146.

Dauphin, Claudine. 1984. “Dor, Byzantine Church.” IEJ 34: 271-274.

Dauphin, Claudine, and Shimon Gibson. 1993. "Dor-Dora: A Station for Pilgrims in the Byzantine Period on their Way to Jerusalem." In Ancient Churches Revealed, edited by Yoram Tzafrir, 90-97. Jerusalem: Israel Exploration Society.

Doerr, Martin. 2003. "The CIDOC CRM - an Ontological Approach to Semantic Interoperability of Metadata." AI Magazine 24 (3): 75-92.

Doerr, Martin, Kurt Schaller, and Maria Theodoridou. 2010. "Integration of Complementary Archaeological Sources." In Beyond the Artifact: Digital Interpretation of the Past:Proceedings of CAA2004, Prato 13-17 April 2004, Italy, edited by Franco Niccolucci, and Sorin Hermon, 64-69. Budapest: Archaeolingua. 
Finkelstein, Israel. 1995. "The Date of the Settlement of the Philistines in Canaan." Tel Aviv 22: 213-239.

Fraassen, Bas C. van. 1980. The Scientific Image. Oxford: Clarendon.

Garstang, John. 1924a. "Tanturah (Dora)." Bulletin of the BSAJ 6: 65-73.

Garstang, John. 1924b. "Tanturah (Dora)." Bulletin of the BSAJ 7: 80-85.

Habu, Junko, Clare Fawcett, and John M. Matsunaga. 2008. Evaluating Multiple Narratives: Beyond Nationalist, Colonialist, Imperialist Archaeologies. New York: Springer.

Hempel, Carl G. 1952. Fundamentals of Concept Formation in Empirical Science. Chicago: University of Chicago Press.

Hodder, Ian. 1997. “'Always Momentary, Fluid and Flexible:' Towards a Reflexive Excavation Methodology." Antiquity 273: 691-700.

Hodder, Ian. 1999. The Archaeological Process: An Introduction. Oxford: Blackwell.

Hodder, Ian, ed. 2001. "Introduction: A Review of Contemporary Theoretical Debates in Archaeology." In Archaeological Theory Today, edited by Ian Hodder, 1-13. Cambridge: Polity.

Hole, Frank, and Robert F. Heizer. 1969. An Introduction to Prehistoric Archaeology. New York: Holt, Rinehart \& Winston.

Iliffe, John H. 1933. "Pre-Hellenistic Pottery in Palestine." QDAP 2: 15-26.

Isaksen, Leif, Kirk Martinez, Nicholas Gibbins, Graeme Earl, and Simon Keay. 2010. "Linking Archaeological Data." In Making History Interactive. Computer Applications and Quantitative Methods in Archaeology. Proceedings of the 37th International Conference, Williamsburg, Virginia, United States of America, March 22-26, edited by Bernard Frischer, Jane Webb Crawford, and David Koller, 130-136. BAR-IS 2079. Oxford: Archaeopress.

Joukowsky, Martha. 1980. A Complete Manual of Field Archaeology: Tools and Techniques of Field Work for Archaeologists. Englewood Cliffs: Prentice-Hall.

Kaplan, Abraham. 1998. The Conduct of Inquiry: Methodology for Behavioral Science. New Brunswick: Transaction.

Kelley, Jane H., and Marsha P. Hanen. 1988. Archaeology and the Methodology of Science. Albuquerque: University of New Mexico Press.

Kenyon, Kathleen M. 1981. Excavations at Jericho III: The Architecture and Stratigraphy of the Tell. London: The British School of Archaeology in Jerusalem.

Lamon, Robert S., and Geoffrey M. Shipton. 1939. Megiddo I. Chicago: The University of Chicago Press.

Lawrence, Dan, Jennie Bradbury, and Robert Dunford. 2012. “Chronology, Uncertainty and GIs: A Methodology for Characterising and Understanding Landscapes of the Ancient Near East." In Landscape Archaeology. Conference (LAC 2012), edited by Wiebke Bebermeier, Robert Hebenstreit, Elke Kaiser, and Jan Krause, 353-359. етоPOI, Special Volume 3.

Leibowitz, Joseph. 1950. “Dor.” IEJ 1: 249. 
Levy, Thomas E., and Austin F. C. Holl. 1995. "Social Change and the Archaeology of the Holy Land." In The Archaeology of Society in the Holy Land, edited by Thomas E. Levy, 4-5. New York: Facts On File.

Losee, John. 2001. A Historical Introduction to the Philosophy of Science. 4th ed. Oxford: Oxford University Press.

Loud, Gordon.1948. Megiddo 2: Seasons of 1935-39; Text. Chicago: University of Chicago Press.

Maedche, Alexander. 2002. Ontology Learning for the Semantic Web. Boston: Kluwer Academic.

Martin, S. Rebecca. 2014. "From the East to Greece and Back Again: Terracotta Gorgon Masks in a Phoenician Context." In Phéniciens d'Orientet d'Occident:Mélanges Josette Elayi, edited by Andre Lemaire, 289-299. Paris: Maisonneuve.

Matskevich, Sveta. 2015. 'Off the Record.' Recording Systems for Archaeological Excavations in the Levant: Past and Future." PhD diss., The Hebrew University of Jerusalem.

Matskevich, Sveta, and Ilan Sharon. 2016. "Modelling the Archaeological Record: A Look from the Levant. Past and Future Approaches." In CAA 2015. Keep the Revolution Going. Proceedings of the 43rd Annual Conference on Computer Applications and Quantitative Methods in Archaeology, edited by Stefano Campana, Roberto Scopigno, Gabriella Carpentiero, and Marianna Cirillo, 103-115. Oxford: Archaeopress.

May, Keith, Ceri Binding, Doug Tudhope, and Stewart Jeffrey. 2012. "Semantic Technologies Enhancing Links and Linked Data for Archaeological Resources." In Revive the Past: Proceedings of the 39th Conference in Computer Applications and Quantitative Methods in Archaeology, Beijing, China, 12-16 April 2011, edited by Mingquan Zhou, Iza Romanowska, Zhongke Wu, Pengfei Xu, and Philip Verhagen, 261-272. Amsterdam: Pallas.

Mazar, Amihai. 1997. Timnah (Tel Batash) I: Stratigraphy and Architecture. Qedem 37. Jerusalem: The Hebrew University of Jerusalem.

Merton, Robert K. 1949. Social Theory and Social Structure: Toward the Codification of Theory and Research. Glencoe, IL: Free Press.

Petrie, William M. Flinders. 1904. Methods and Aims in Archaeology. London: MacMillan and Co.

Pitt-Rivers, Augustus H. L.-F. 1887. Excavations in Cranborne Chase, near Rushmore, on the Borders of Dorset and Wilts. 1880-1896. Vol. 1. London: Harrison and Sons.

Raab, L. Mark, and Albert C. Goodyear. 1984. "Middle-Range Theory in Archaeology: A Critical Review of Origins and Applications." AmAnt 49 (2): 255-268.

Raban, Avner. 1993. "Acco: Maritime Acco." In New Encyclopedia of Archaeological Excavations in the Holy Land, edited by Ephraim Stern, 29-31. Vol. 1. Jerusalem: Israel Exploration Society \& Carta.

Renfrew, Colin, and Paul Bahn. 2008. Archaeology: Theory, Methods, and Practice. $5^{\text {th }}$ ed. London: Thames \& Hudson. 
Roskams, Steve. 2001. Excavation. Cambridge Manuals in Archaeology. Cambridge: Cambridge University Press.

Shahack-Gross, Ruth. 2011. "Herbivorous Livestock Dung: Formation, Taphonomy, Methods for Identification, and Archaeological Significance." JASC 38 (2): 205-218.

Shahack-Gross, Ruth, Rosa-Maria Albert, Ayelet Gilboa, Orna Nagar-Hilman, Ilan Sharon, and Steve Weiner. 2005. "Geoarchaeology in an Urban Context: The Uses of Space in a Phoenician Monumental Building at Tel Dor (Israel)." JASc 32: 1417-1431. Sharon, Ilan. 1995a. "Models for Stratigraphic Analysis of Tell Sites." PhD diss., The Hebrew University of Jerusalem.

Sharon, Ilan. 1995b. “The Registration System." In Excavations at Dor, Final Report IA: Areas $A$ and $C$, edited by Ephraim Stern, John Berg, Ayelet Gilboa, Bracha GuzZilberstein, Avner Raban, Renate Rosenthal-Heginbottom, and Ilan Sharon, 13-20. Qedem Reports 1. Jerusalem: The Hebrew University of Jerusalem.

Slaatte, Howard A. 1979. The Dogma of Immaculate Perception: A Critique of Positivistic Thought. Lanham, MD: Rowman \& Littlefield.

Stern, Ephraim. 2001. "A Gorgon's Head and the Building of the First Greek Temples at Dor and along the coast." Qadmoniot 34: 44-48 (in Hebrew).

Stern, Ephraim. 2010. Excavations at Dor: Figurines, Cult objects and Amulets, 1980-200o Seasons. Jerusalem: Israel Exploration Society.

Stern, Ephraim, John Berg, Ayelet Gilboa, Bracha Guz-Zilberstein, Avner Raban, Renate Rosenthal-Heginbottom, and Ilan Sharon. 1995. Excavations at Dor, Final Report IA: Areas A and C. Qedem Reports 1. Jerusalem: The Hebrew University of Jerusalem.

Stewart, Andrew, and S. Rebecca Martin. 2005. "Attic Import Pottery at Tel Dor, Israel: An Overview." BASOR 337: 79-94.

Van Beek, Gus W. 1988. "Excavation of Tells." In Benchmarks in Time and Culture. An introduction to Palestinian Archaeology, edited by Joel F. Drinkard, Gerald L. Mattingly, James Maxwell Miller, and Joseph A. Callaway, 131-167. Atlanta: Scholars Press.

Willey, Gordon R., and Philip Phillips. 1958. Method and Theory in American Archaeology. Chicago: University of Chicago Press.

Zarzecki-Peleg, Anabel. 2016. Yadin's Expedition to Megiddo: Final Report of the ArchaeologicalExcavations (1960, 1966, 1967 and 1971/2 Seasons). Qedem 56. Jerusalem: The Hebrew University of Jerusalem.

Zorn, Jeff R., ed. 1991. "Tel Dor Excavations—Staff Manual." <http://dor.huji.ac.il/ Download/Tel_Dor_Staff_Manual/Tel_Dor_Staff_Manual_1991.pdf $>$.

Zorn, Jeff R., Ilan Sharon, and Ayelet Gilboa. In press. "Introduction: History of the Area G Excavations (1986-2004); Post Excavation Analysis (1993-2010) and Introductory Remarks on Excavation, Documentation and Methods." In Excavations at Dor, Final Report, Volume 2, Area G, edited by Ayelet Gilboa, Ilan Sharon, and Jeff R. Zorn. Qedem Reports. Jerusalem: The Hebrew University of Jerusalem. 